Int. J. Dev. Biol. 59: 465-470 (2015)

doi: $10.1387 / \mathrm{ijdb} .150008 \mathrm{rg}$

\title{
Visualization of primordial germ cells in the fertilized pelagic eggs of the barfin flounder Verasper moseri
}

\author{
RIE GOTO*,1,\#, TAIJU SAITO1,\#\#\#, YUTAKA KAWAKAMI' ${ }^{1}$ TOMOE KITAUCHI ${ }^{1}$, MISAE TAKAGI ${ }^{1}$, TAKASHI TODO², \\ KATSUTOSHI ARAI ${ }^{2}$ and ETSURO YAMAHA ${ }^{1}$
}

\begin{abstract}
${ }^{1}$ Nanae Fresh Water Laboratory, Field Science Center for Northern Biosphere, Hokkaido University, Nanae, Kameda, Hokkaido 041-1105 and '2Faculty of Fisheries Sciences, Hokkaido University, Hakodate, Hokkaido 041-8611, Japan

ABSTRACT Primordial germ cells (PGCs) appear during early embryogenesis and differentiate into gametes through oogenesis or spermatogenesis. Teleost PGCs can be visualized by injecting RNA transcribed from the fusion product of a fluorescent protein gene attached to the $3^{\prime}$ untranslated region (3'UTR) of zebrafish nanos3 (zf-nos3). Although this method has been widely applied to teleost PGCs, the visualization of PGCs in pelagic species that have eggs with a hard chorion is more problematic due to the technical difficulty of microinjection into their eggs. In this study, we developed a reliable method for microinjection of fertilized eggs in a pelagic species, the barfin flounder. Using a microneedle with a constriction “brake", we were able to introduce gfp-nos3 3'UTR mRNA into embryos and to determine the migration route of PGCs. We also isolated the barfin flounder nos3 (bf-nos3) gene to compare its 3'UTR sequence with that of zebrafish. The 3'UTR of the bf-nos3 sequence was longer than that of zf-nos3. However, PGCs were also visualized after injection of $g f p$-bf-nos3 3'UTR mRNA both in zebrafish and barfin flounder. These results suggest that the function of nos 3 is conserved between these species regardless of the sequence differences. The method developed here for labeling PGCs with gfp-nos3 mRNA will provide a means to study PGC development in the embryos of a wide range of marine fish species.
\end{abstract}

KEY WORDS: teleost, $P G C$, flounder, pelagic egg, microinjection

\section{Introduction}

Recent advances in methodologies for manipulating teleost PGCs have considerable potential for use in both aquaculture and conservation of endangered fish species (Yamaha et al., 2010). For example, it has been shown that intra-species and inter-species germline chimeras generated by transplantation of a single PGC can produce fertile gametes (Saito et al., 2008). Such manipulations are generally dependent on the ability to identify PGCs, to isolate them by flow cytometry and to cryopreserve them. PGCs subjected to these treatments have been demonstrated to retain the capacity to differentiate into functional gametes in germline chimeric fish (Goto-Kazeto et al., 2010; Kawakami et al., 2010). Serial manipulation of PGCs, including genetic modification (or genetic engineering), and the production of gametes through germline chimeras opens new fields of research and offers new practical applications in fish biology. However, most of the initial research has been carried out on model fresh-water fish species. Transferring the methods developed in these model species to marine aquaculture species, especially pelagic fish, poses particular technical difficulties especially for embryo manipulation.

The structure of fish eggs varies among species and these variations are generally associated with habitat-related adapta-

\footnotetext{
Abbreviations used in this paper: nos, nanos3 (nos) gene is expressed in germ cells and is essential for germ cell development; PGC, Primordial germ cell (PGC) is a precursor of germ cell that appears during early embryogenesis and differentiates into gametes through oogenesis or spermatogenesis.
}

\footnotetext{
*Address correspondence to: Rie Goto. 25-1 Uchidomari, Ainan, Ehime Prefecture, Japan 798-4206. Tel: +81-(0)895-73-7112. Fax: +81-(0)895-73-7113.

E-mail: goto.rie.me@ehime-u.ac.jp ; riegoto0419@gmail.com - web: www.ehime-u.ac.jp/english ; umilike.jimdo.com

\#Current address: Nishiura Station, South Ehime Fisheries Research Center, Ehime University, Uchidomari, Ainan, Ehime 798-4206, Japan.

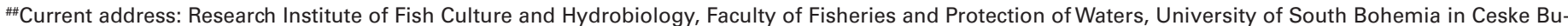
dejovice, Vodnany, Czech Republic.
}

Supplementary Material (one figure + one table) for this paper is available at: http://dx.doi.org/10.1387/ijdb.150008rg

Accepted: 12 November 2015.

ISSN: Online 1696-3547, Print 0214-6282 
tions. An egg envelope (chorion) is formed during oogenesis and is hardened after fertilization or activation (Yamagami et al., 1992). Depending on its nature, the egg chorion may pose a barrier to microinjection into the egg. This problem can generally be overcome by enzymatic removal of the chorion, for example, using trypsin or hatching enzyme from embryonic extracts; this approach has been established for species such as zebrafish and medaka (Westerfield, 2007; Wakamatsu, 1997). An alternative method used in medaka and salmon is prevention of the hardening of the egg chorion using glutathione. Although this treatment ensures that the chorion is sufficiently soft for microinjection, it has to be applied immediately after fertilization (Iwamatsu, 1983; Nagasawa et al., 2013). Mechanical removal of the egg chorion is also possible in species that have a relatively wide perivitelline space, for example, the Japanese eel (Saito et al., 2011). Unfortunately, the perivitelline space is too narrow for mechanical removal of the chorion in the barfin flounder and other major aquaculture species such as tuna and seabream. Overall, eggs of marine pelagic fish present a number of technical difficulties for microinjection: 1) a hard egg chorion; 2) high internal pressure inside the egg which causes backflow of cytoplasm into the microinjection needle; 3) a tendency for the embryos to float which makes them difficult to

\section{A}

A front view of biological microscope for preparation of glass needles with a brake

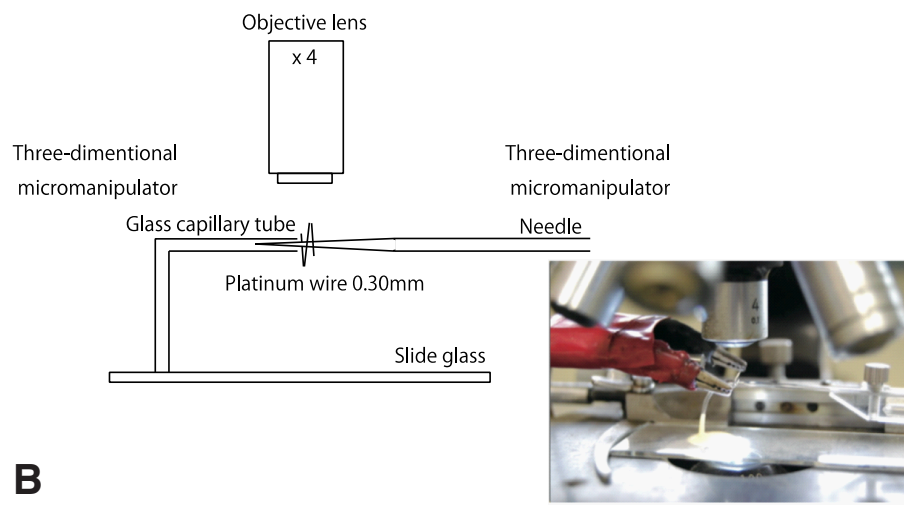

Upper views for preparation of glass needles with a brake

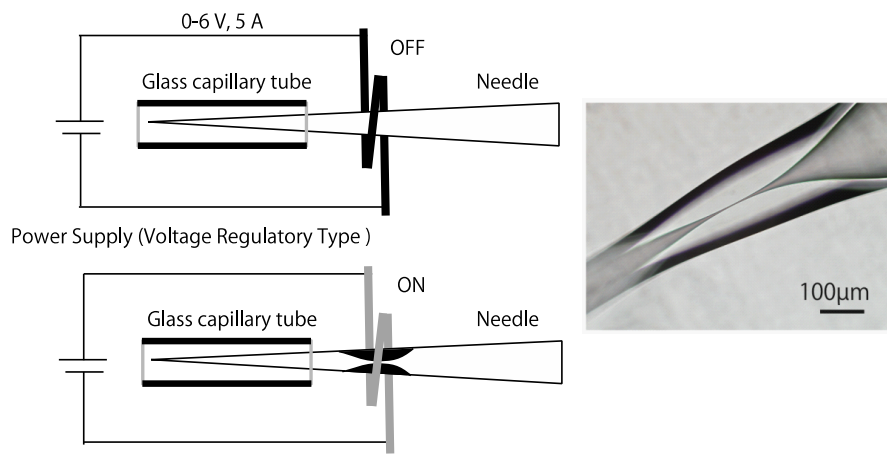

Fig. 1. Illustration of the set-up for preparing glass needles for microinjection. (A) Schematic drawing of the front view showing the position of the microscope objective and the 3-dimensional micromanipulator. The photographic insert shows alligator clips connecting to a platinum wire on the left and a needle holder and needle on the right. (B) Schematic drawing of the image seen using the microscope as in (A). The photographic insert shows a glass needle with a brake. manipulate; and 4) the embryo is oriented with the vegetal pole upward in the egg chorion.

Identification of fish PGCs can be achieved by microinjection of a construct derived from the nos 3 gene conjugated to a green fluorescent protein (GFP) tag. The gene nos3 (previously named nanos 1 in zebrafish) is a maternally inherited gene that is essential for development and maintenance of the PGCs; it encodes a zinc-finger protein with putative RNA-binding activity (Köprunner et al., 2001). Maternal nos3 transcripts are diffusely distributed throughout the zygote; however, the Nos3 protein is post-transcriptionally restricted to PGCs (Mishima et al., 2006). In zebrafish, the microRNA miR-430 targets the 3'UTR of nos3 during embryogenesis; the miR-430 target site within the nos 3 3'UTR reduces poly $(A)$ tail length, mRNA stability and translation. The miR-430 mediated repression of nos 3 is not effective in germ cells. The evolutionarily conserved RNA-binding protein dead end1 ( $d n d 1$ ) counteracts the function of nos3 in PGCs by binding mRNAs and prohibiting miR-430 from associating with its target site (Kedde et al., 2007). The fusion of the GFP gene to zebrafish nos3 3'UTR enables the visualization of PGCs in a wide range of fish species including the Acipenseridae, one of the oldest families of bony fish (Saito et al., 2013). These findings suggest that the nos3 gene function, such as post-transcriptional translation, is conserved among fish species.

The first aim of this study was to develop an efficient microinjection method to enable visualization of PGCs during embryogenesis in the barfin flounder; the pelagic egg of this species has a single membrane-bound yolk mass like that of the medaka (Otani et al., 2009). Secondly, we sought to isolate the barfin flounder nos3 gene with the aim of comparing the 3'UTR sequence with zebrafish. Thirdly, we sought to determine the migration route of PGCs in the barfin flounder by tracking GFP-labeled PGCs during embryogenesis.

\section{Experimental Protocols}

\section{Artificial fertilization in the barfin flounder}

This study was carried out in accordance with the Guide for the Care and Use of Laboratory Animals in Hokkaido University and Field Science Center for Northern Biosphere, Hokkaido University. Adult barfin flounders (Verasper moseri) were kept at the Akkeshi Station of the Japan Sea-Farming Association in Hokkaido. Experiments were performed in April 2007 and April 2008. Eggs were obtained by gently squeezing the abdomen of mature females and were kept at $4^{\circ} \mathrm{C}$ until fertilization. Sperm were collected by gently hand-stripping the abdomen of males and were preserved in artificial seminal plasma at $4^{\circ} \mathrm{C}$. The eggs and sperm could be stored for 3 days before fertilization. Fresh seawater was kept at $4^{\circ} \mathrm{C}$ with gentle aeration and was passed through a $0.45 \mu \mathrm{m}$ filter using a $1000 \mathrm{~mL}$ vacuum filter (Corning International, Inc.) before use. The timing of embryonic development from fertilization to the larval stage was determined at $8^{\circ} \mathrm{C}$ (Supplementary Fig. S1, Supplementary Table S1).

\section{Preparation of microinjection needles}

Precision glass capillary tubes (capacity $50 \mu \mathrm{l}$, length $100 \mathrm{~mm}$, Microcaps $\AA$ 1-000-0500, Drummond Scientific) were used for producing microinjection needles. Both ends of the glass capillary tube were smoothened by heating in order to protect the rubber 
A

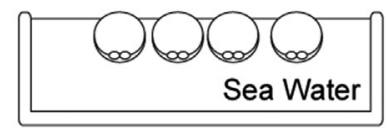

B

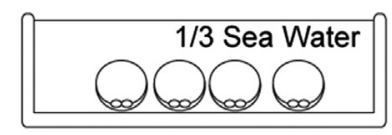

C

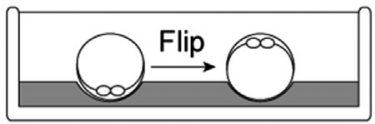

D
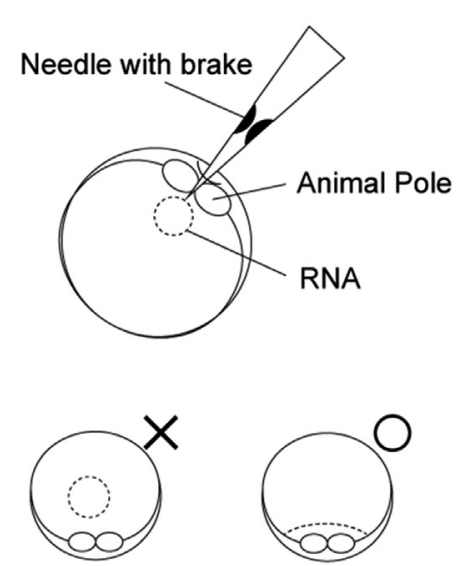

Remove

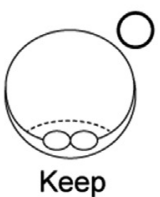

Keep

Fig. 2. Illustration of the microinjection method for pelagic fish eggs that have a single membrane-bound yolk mass. (A) After fertilization, the embryos float to the surface of the seawater. (B) After transfer to onethird concentration of seawater, the eggs sink to the bottom of the dish. (C) Embryos are placed into small pockets in the surface of an agar-coating dish and reoriented so that the animal pole faces upward. (D) The RNA solution is injected through the animal pole region using a needle with a brake. Embryos in which the RNA solution was positioned just below the blastoderm were deemed to be successfully treated.

ring of the microinjector (CellTrum ${ }^{\circledR}$ vario, Eppendorf) from sharp edges. The capillary tube was pulled to make two needles using a Dual-Stage Glass Micropipette Puller (Narishige). A constriction (termed a "brake") was added in the upper part of the tip (approx. 2-3 $\mathrm{mm}$ from the tip) with a 3 to $5 \mu \mathrm{m}$ inner diameter as described elsewhere (Kishimoto, 1989). An outline of the method for making the brake is shown in Figure 1. The apparatus consists of an upright microscope with a $x 4$ objective lens, a supporting glass capillary tube attached horizontally and mounted on a glass microscope slide. A loop of platinum wire $(0.3 \mathrm{~mm})$ was placed in front of the supporting glass capillary tube and connected to a voltage regulatory type power supply. The relative positions of the microneedle and the platinum wire loop were controlled with a three-dimensional micromanipulator under the microscope. The tip of the microneedle was inserted through the loop into the supporting glass capillary tube to hold the microneedle in a horizontal position (Fig. 1B). The brake was formed by applying an electric current

Fig. 3. Comparison of the deduced Nos3 peptide sequence of the barfin flounder (GenBank Accession No: KF915811) to Nos3 of medaka (NM001122828.1), zebrafish (NM131878.1), and Salmo salar (3a; KC237283.1, 3b; KC237284.1). Dashes represent gaps compared to the barfin flounder Nos3. Below the protein sequences is a key denoting conserved sequence (*), conservative mutation (:), semi-conservative mutation (.) and non-conservative mutation (). The conserved CCHC zinc finger domains are also indicated.

to the loop of platinum wire. The brake enables the operator to control the pressure required for injecting the RNA solution into the egg and also prevents backflow of cytoplasm from the egg.

\section{Microinjection of RNA into fertilized eggs}

Artificial fertilization was performed using a dry method at $8^{\circ} \mathrm{C}$ in order to control the timing of RNA injection into embryos. Fertilized eggs were incubated in seawater supplemented with $0.01 \%$ streptomycin and $0.01 \%$ penicillin at $8^{\circ} \mathrm{C}$ until hatching except for manipulated embryos. Basically, the protocol for microinjection was as described for medaka with slight modifications (Kinoshita et al., 2009). Fertilized eggs were transferred to one-third concentration of seawater supplemented with antibiotics; the eggs sink in this seawater concentration (Fig. 2 A,B). High quality fertilized eggs were transferred to a glass plate coated with $1 \%$ agar for the RNA injection (Fig. 2C). Each egg was placed in a closely-fitting hole on the agar surface and then oriented using forceps such that the blastoderm faced toward the microneedle. RNA was then microinjected into the base of the embryonic blastodisc (Fig. 2 C,D).

\section{Cloning of bf-nos3 and creation of the gfp-bf-nos3 3'UTR fusion construct}

Matured ovary was derived from a farmed barfin flounder and stored at $-20^{\circ} \mathrm{C}$. Frozen ovary was homogenized in TRIZOL (Life technologies, Japan). Poly(A)+RNA was prepared from total RNA using a QuickPrep Micro mRNAPurification Kit (GE Healthcare, Japan). The full cDNAsequence of nos3(GenBank ID: 138KF915811) was isolated by RACE using the SMART ${ }^{\text {TM }}$ RACE cDNA Amplification Kit (Clontech, Japan). The 5'- and 3'-RACE reactions were carried out on mRNA using the following primers: forward primer, 5'-GTCTGACGTGGTGTATGGATCCCACTGG-3'; forward nested primer, 5'- GTCATGTGTCCTTACCTGCGGCAGTACG-3'; reverse

barfin floundel MNGVVWSLFHHLPRFMESDSRSFQPWRDYMGLSETVRDILARNSAAQPSLSAPKASHLEP medaka zebrafish salmo salar $3 a$ salmo salar $3 \mathrm{~b}$ MSDVESG---LLHLIMEPSSSRFHLWKDYMGLSDTVKEILGRNPPTESYLEC-------MAFSLLQFILSAHGSMETRNQDFQPWKDYMGLADMIRGMKRQEMQSDADSDE-----------------MESENKSFQPWRDYMKLADLVREMQLGKFTPEPLTVEG----------------MESENKSFQLWRDYMKLADAVREMKLGNFTSEPLTVDG------$\star * . \quad *: *: * \star \star \star::$ : : : : : :

barfin floundel GDRGRALVS--VRLNAM----RHSNFGADCAPGLRGESPRPDSSAHRILTDVLRAPNPAR medaka GGHRSSK----YDLNRD----MRSNAALQSA---------1---PAGTDLLRAPPLRS zebrafish --QAAAL---------salmo salar 3a --HDSGICSTMVEFEEFPPRALLSPITPAATPPLWHEMEPLDSEIVPVRKD------salmo salar $3 b$--HHSGICSTMVELEQFPPRALLSPIAPAATPPLRHEKEPLDSKIVPVRKD-------: :

barfin floundel VGAPDVVDPKQVPEPH------R------GTKDRKRTTLPKTPAPPAAPPPERMFCSFCK medaka PRAPHLPGSFEVPPPEPPKSRSR------DSKDTGRGRLD--QPETPSSPDGPMYCSFCk zebrafish ---------GPI-----R-----SR-DSPEQNTSPGGGKPKSSPAERKF CSFCK salmo salar 3a ----AALRPSSTEGPEPPTAASRSSAGTRGQRERKK------APEEVSSPERKICSFCK salmo salar 3 b ----AALHPNSSEGPEPPTAASRPSAGTRGQRERKKA--TRSKTPEEVPSPELQFCSFCK $\star \quad \star \quad: \quad$ :

barfin flounde HNGESDVVYGSHILKNLAGDVYCPYLRQYYCPICGATGAKA HTKRFCPRVDSAYSSVYAK medaka HNGESEMVYRS HWLKNQKGDVI CEYLRQYV CPICGATGAKA HIKR C PKVDRTYSSVYVK zebrafish HNGETEAVYTSHYLKNRDGDVM CPYLRQYX CPICGATGAKA HIKRF CPMVDKNYCSVYAK salmo salar 3a HNGESESVFGSHNLKDQDGGVVC PYLRHYI C PIC GATKAQA HIKR A CPVETTYSSVYVK salmo salar 3b HNGESESVFGSHNLKDQDGGVVCPYLRHYICPICGATGAQAHTKRACPRVETTYNSVYVK

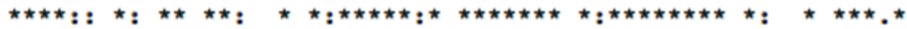

barfin floundel SRR medaka SRR zebrafish STw salmo salar 3a --salmo salar $3 \mathrm{~b}$ R--
$\mathrm{CCHC}-\mathrm{CCHC}$ zinc finger domain 
primer, 5'- CGTACTGCCGCAGGTAAGGACACATGAC-3'; and reverse nested primer, 5'- CCAGTGGGATCCATACACCACGTCAGAC-3'. The resulting amplicon was T/A ligated into pDrive (Qiagen, Japan) and three of the resulting clones were sequenced in both directions. Characterization and analysis of homology of the sequence was performed using Clustal OMEGA (http://www. ebi.ac.uk/Tools $/ \mathrm{msa} / \mathrm{clustalo} /$ ). The 3'UTR sequence of bf-nos3 was amplified with the following primers that added a restriction enzyme sequence: forward primer with Xhol, 5'-ctcgagCCAGCAGGTGGCAGGTAT-3'; and reverse primer with Xbal, 5'-tctagaGCTTGTCATTGTTTTATTAAG-3'. The amplified product was cloned into the pDrive vector. To generate a plasmid containing gfp-bf-nos3 3'UTR, the bf-nos33'UTR sequence was replaced with the zf-nos3 3'UTR sequence in the pCS2+ gfp-zf-nos3 3'UTR as described by Köprunner et al., (2001). To visualize PGCs, capped mRNA was prepared from pCS2+ gfp-bf-nos3 3'UTR and pCS2+ gfp-zf-nos3 3'UTR (Xbal, SP6 polymerase) using the mMessage mMachine kit (Ambion). Synthesized RNA was diluted in $0.2 \mathrm{M} \mathrm{KCl}$ at 300 $\mathrm{ng} / \mathrm{\mu l}$ and $1 \%$ rhodamine (SIGMA, Japan) was added to verify the accuracy of the injection.

\section{Whole mount in situ hybridization (WISH)}

Briefly, WISH was carried out as follows. Embryos were fixed in freshly prepared $4 \%$ paraformaldehyde/phosphate buffered saline (PFA/PBS) for 1 hour on ice, and washed twice with PBS. The egg chorion was removed under a stereomicroscope using forceps and the embryo was re-fixed in 4\% PFA/PBS overnight at $4^{\circ} \mathrm{C}$. A $533 \mathrm{bp}$ anti-sense vasa probe based on the zebrafish (Danio rerio) sequence (GenBank accession no. NM131057.1) was labeled using a digoxigenin RNA labeling kit (Roche). Images were captured using a LEICA MZ16F stereomicroscope equipped with a CCD camera.

\section{Results}

\section{Microinjection of RNA into the fertilized eggs of the barfin flounder}

Fertilized flatfish eggs normally rise to the surface of the seawater; this characteristic floating behavior is closely associated with good egg quality, and most floating eggs develop normally (Fig. 2A). In order to be able to manipulate and inject the eggs, it was necessary to induce them to sink. We achieved this by transferring the eggs to one-third concentration seawater (Fig. 2B). Generally, the animal pole of the embryos faced downward; therefore, we placed the eggs into small holes in the agar and manually reoriented the eggs using forceps to have the animal pole at the top (Fig. 2C).

\section{TABLE 1}

PERCENTAGE OF BARFIN FLOUNDER EMBRYOS WITH GFP-LABELED PGCS AT GONADAL REGION (GR)

\begin{tabular}{lccc} 
Group & $\begin{array}{c}\text { Total no. } \\
\text { of embryos injected }\end{array}$ & $\begin{array}{c}\text { No. of embryos } \\
\text { surviving to 3 dpf (\%) }\end{array}$ & $\begin{array}{c}\text { No. of embryos with } \\
\text { GFP-labeled PGCs at GR }\end{array}$ \\
\hline Control & 42 & $34(81.0)$ & $-(-)$ \\
Exp. 1 & 26 & $14(53.8)$ & $10(71.4)$ \\
Exp. 2 & 27 & $27(100.0)$ & $18(66.7)$ \\
Exp. 3 & 92 & $27(29.3)$ & $13(48.1)$ \\
Exp. 4 & 37 & $6(16.2)$ & $1(16.7)$ \\
\hline
\end{tabular}

*Microinjection was performed at the 1-cell stage except for group 4 in which 2-cell embryos were used.
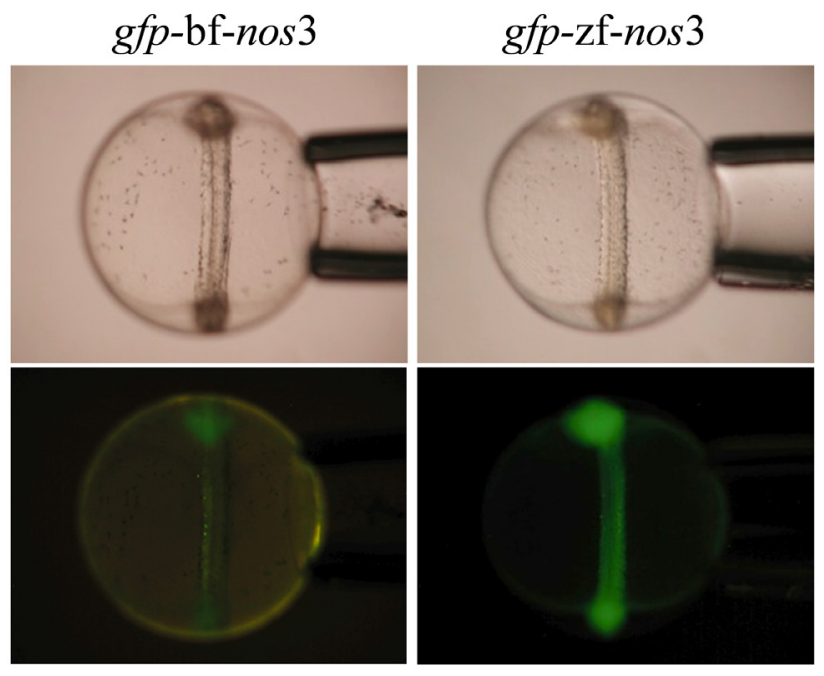

Fig. 4. Visualization of barfin flounder PGCs using gfp-nos3 3'UTR mRNA. Bright and dark field images of somite stage embryos after microinjection of mRNA transcribed from a construct of gfp and nos3 3'UTR of barfin flounder (left images) or of zebrafish (right images).

In order to inject a solution into the blastodisc of the embryo, we used a microinjection needle that has a constriction brake in its tip to prevent backflow of cytoplasm and to control the amount of solution injected (Fig. 2D). The microneedle was inserted between the blastomeres of one- to two-cell embryos (Supplementary Fig. S1 A-b, A-c, B) and RNA was injected at the border between the blastodisc and yolk (Fig. 2D). After injection, the embryos were returned to seawater. Although some of the injected embryos remained submerged in the seawater at the blastula stage (Supplementary Fig. S1 K,L), they eventually floated to the surface around gastrulation (3 days post-fertilization) and developed normally (Supplementary Fig. S1 O,P).

\section{Isolation and characterization of bf-nos3}

The full sequence nos3 cDNA of the barfin flounder was isolated by RACE (GenBank ID: KF915811). The deduced protein showed $52.6 \%$ identity with the medaka Nos3 protein (GenBank ID: NM001122828.1), 45.0\% with the zebrafish protein (GenBank ID:NM131878.1), 42.2\% with the Salmo salar3a protein (GenBank ID: KC237283.1), and $43.2 \%$ with the Salmo salar $3 \mathrm{~b}$ protein (GenBank ID: KC237284.1) (Fig. 3). A Cys Cys Hys Cys (CCHC) metal-binding domain that is conserved in the nos family was also present in bf-nos3. A nested 3'-RACE reaction amplified two different lengths of cDNA including the poly $(A)$ tail. The longer 3'UTR contained 816 nt excluding the poly $(A)$ tail and the shorter 3'UTR form contained a $293 \mathrm{nt}$ sequence that completely matched part of the upstream sequence of the longer 3'UTR form. In this study, the longer form of 3'UTR was analyzed and used for constructing a gfp-bf-nos3 3'UTR plasmid. The 3'UTR sequence of bf-nos3 contained uridine rich regions (URRs) and non-canonical miR-430 binding sites as previously reported (see Figure 8 in Li et al., 2015).

\section{Comparison of PGC-labeling efficiency in barfin flounder and zebrafish after injection of gfp-nos3 3'UTR}

To compare the function of bf-nos3 3'UTR with that of zebrafish, we synthesized the fusion constructs gfp-zf-nos3 3'UTR and gfpbf-nos3 3'UTR; these were separately injected into both one-cell 
stage barfin flounder and zebrafish embryos. Both RNAs enabled the identification of PGCs in developing embryos of these species, although there was weak GFP background after injection of $g f p$ bf-nos3 mRNA in case of barfin flounder (Fig. 4).

\section{Visualization of PGCs during embryogenesis in the barfin flounder}

The present study is the first report of successful visualization of PGCs using mRNA in a marine fish species with pelagic eggs that have a membrane-bound yolk mass. Four groups of embryos were injected with mRNA and between 16.7 and $71.4 \%$ of the surviving embryos showed GFP-labeled PGCs during their development (Table 1). The number of PGCs was counted in 11 randomly selected embryos with GFP-positive staining; the embryos respectively had 2, 10, 2, 2, 5, 4, 2, 1, 1, 4, and 7 PGCs. The PGCs appeared as small foci of relatively strong GFP fluorescence in embryos at $50 \%$ epiboly (Fig. 5 A,A', Supplementary Fig. S1 O). In the barfin flounder, the embryonic shield is apparent at the $50 \%$ epiboly
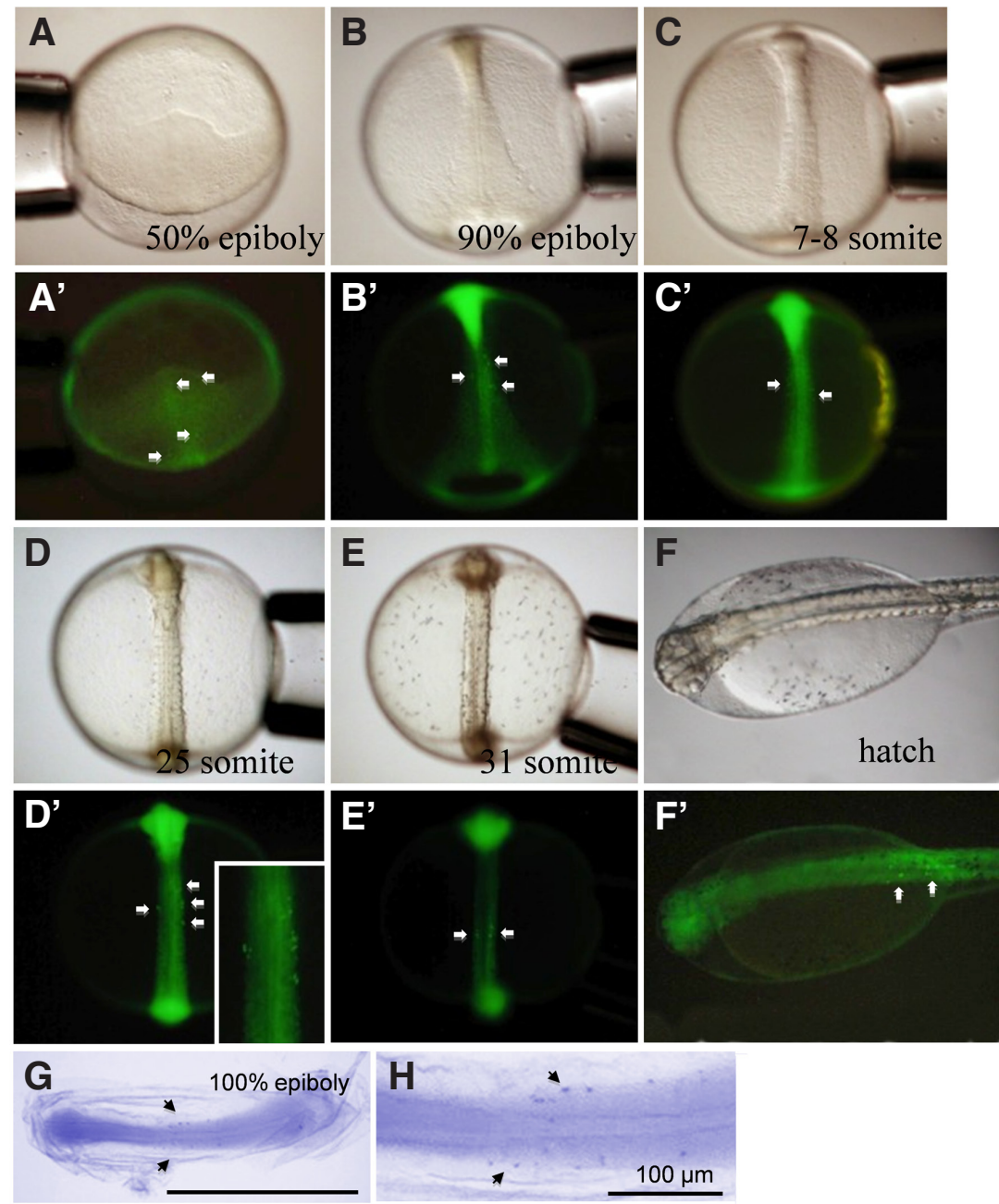

Fig. 5. Visualization of barfin flounder PGCs during embryogenesis. Dorsal views of embryos microinjected with gfp-nos 3 mRNA from 50\% epiboly to hatching using brightfield illumination (A,B,C,D,E,F) or fluorescence microscopy $\left(\mathbf{A}^{\prime}, \mathbf{B}^{\prime}, \mathbf{C}^{\prime}, \mathbf{D}^{\prime}, \mathbf{E}^{\prime}, \mathbf{F}^{\prime}\right)$. White arrows indicate location of GFP-labeled PGCs. Distribution of vasa-positive cells analyzed by whole-mount in situ hybridization in a somite embryo (G); enlarged image of part of 'G' (H). Scale bar, $100 \mu \mathrm{m}$. stage; the PGCs were located in the dorsal side of the lower part of the blastoderm where the embryonic shield formed. In embryos at $90 \%$ epiboly, PGCs were observed along both sides of the body and were located approximately one-third of the body length from the yolk plug; the PGCs moved anteriorly during the early somite stage (Fig. 5 B,B',C,C', Supplementary Fig. S1 Q). In late somite of the embryonic body (Fig. 5 D,D',E,E', Supplementary Fig. S1 $\mathrm{P}, \mathrm{S})$. The labeled PGCs were mainly located underneath somites $10-15$ at the time of hatching (Fig. 5 F,F', Supplementary Fig. S1X). assembled in a row along the somites as was seen in embryos labeled with gfp-nos3 mRNA (Fig. $5 \mathrm{G}, \mathrm{H}$ ).

\section{Discussion}

In this study, we made use of a microinjection needle that had brake; this design of needle was originally developed for use in starfish oocytes (Kishimoto, 1989). Our use of this needle enabled the efficient microinjection of an RNA solution into embryos of the barfin flounder. Although pressure-controlled injection is well-established for microinjection into fish eggs that possess a hard chorion and high internal pressure such as medaka (Kinoshita et al., 2009), it was necessary to modify it by introducing a brake into the needle to apply a sufficient and constant high pressure to overcome the internal pressure of pelagic eggs. The use of the modified method enabled the introduction of the solution under a controlled and low flow rate. Our objectives were to inject an RNA solution into the lower part of the blastodisc of two-cell embryos (essentially at the boundary between the blastodisc and the yolk mass) and for the RNA solution to remain in the cytoplasm and not disturb embryonic development. In embryos in which RNA was injected into the yolk after accidental penetration of the membrane boundary, GFP labeling was seen exclusively in the yolk. This observation indicated that the membrane surrounding the yolk did not allow passage of the high molecular weight RNA used in this study. In other teleosts, such as the zebrafish, goldfish and eel, that have yolk granules in the egg, injection of RNA under the blastodisc is able to label PGCs since the injected solution stays between the yolk granules and can later flow into the cytoplasm.

It has previously been reported that a gfp-zebrafish nos3 3'UTR fusion construct can be used to visualize PGCs in wide range of teleosts from ancient to modern species (Saito et al., 2013). However, the level of non-specific expression of GFP in the somatic cells varies among species; higher levels of non-specific expression are observed in the goldfish, herring and ice goby compared to zebrafish and its close relative pearl danio. In zebrafish, nos 3 is translationally controlled by the RNA-binding protein dead end 1 (Dnd1) and the microRNA miR-430 (Mishima et al., 2006; Kedde et al., 2007). Dnd1 binds to the URRs of the 3'UTR sequence to protect the nos3 gene from miRNA-mediated repression in PGCs. In this study, we 
showed that the nos33'UTR sequences of both zebrafish and barfin flounder functioned for labeling PGCs in each species, suggesting that there is some conservation of the translational control of the nos3 gene. Supporting this observation, Li et al., has reported that there are some $\mathrm{U}$-rich motif and non-canonical miR- 430 binding site in nanos3 3'UTR of barfin flounder (Li et al., 2015). The increased non-specific expression of GFP in some species might be due to a lack of an miRNA-targeting site.

There have been a number of reports on PGC migration and localization in fish, including marine species (Lin et al., 2012; Presslauer et al., 2012). In the barfin flounder, we found that the migration pattern of PGCs was similar to other species of fish reported previously. Thus, GFP-labeled PGCs appeared at late epiboly, the PGCs aligned along the both sides of the embryonic body, and clusters of PGCs moved laterally under the embryonic body to form gonads. The number of PGCs varied among species, but normally several dozen PGCs were observed in each teleost embryo. In this study, use of a needle with a brake enabled the microinjection of marine pelagic eggs; however, the efficiency of PGC labeling was not high in barfin flounder. Therefore, further technical improvements will be needed in future.

To date, research into developmental biotechnology and genetic engineering in fish has largely been restricted to model teleost species. Major aquaculture species, such as the flounder, tuna, and sea bream, pose additional technical difficulties because their pelagic eggs characteristically possess a hard chorion. The method developed in this study enables the investigation of gene functions, such as through genetic modification, in the latter species and should provide new insights for application to their aquaculture.

\section{Acknowledgements}

The authors would like to express their gratitude to Dr. Takahiro Matsubara, Dr. Tadashi Ando and Mr. Takashi Ichikawa in the Hokkaido National Fisheries Research Institute, Fisheries Research Agency, Dr. Takaaki Kayaba, Mr. Taihei Matsuda in the Hakodate Fisheries Research Institute, Fisheries Research Department, Hokkaido Research Organization for giving us egg samples, and Dr. Kunio Inoue in Kobe University for kindly donating the gfp-zf nos3 3'UTR construct. The authors would also like to express their gratitude to Mr. Shizuo Kimura and the members of the Nanae Fresh water Laboratory, Field Science Center for Northern Biosphere, Hokkaido University for advice and help with the breeding of the fish. This work was supported by grants from the Bio-oriented Technology Research Advancement Institution (BRAIN) of Japan.

\section{References}

GOTO-KAZETO R, SAITO T, TAKAGI M, ARAI K, YAMAHA E (2010). Isolation of teleost primordial germ cells using flow cytometry. Int J Dev Biol 54: 1487-1492.

IWAMATSU T (1983). A new technique for dechorionation and observations on the development of the naked egg in Oryzias latipes. J Exp Zool 228: 83-89.
KAWAKAMI Y, GOTO-KAZETO R, SAITO T, FUJIMOTO T, HIGAKI S, TAKAHASH Y, ARAI K, YAMAHA E (2010). Generation of germ-line chimera zebrafish using primordial germ cells isolated from cultured blastomeres and cryopreserved embryoids. Int J Dev Biol 54: 1493-1501.

KEDDE M, STRASSER MJ, BOLDAJIPOUR B, VRIELINK JAFO, SLANCHEV K SAGE C LE, NAGEL R, VOORHOEVE PM, DUIJSE J VAN, ØROM UA, LUND AH, PERRAKIS A, RAZ E, AGAMI R (2007). RNA-binding protein Dnd1 inhibits micro RNA access to target mRNA. Cell 131: 1273-1286.

KINOSHITAM, KURATAK, NARUSEK, TANAKAM (2009). Medaka:Biology, management, and experimental protocols. WILEY-BLACKWELL, A John Wiley \& Sons, Ltd, Publication, pp. 277-296.

KISHIMOTO T (1989). Microinjection and cytoplasmic transfer in starfish oocytes. Method Cell Biol 27: 379-394.

KÖPRUNNER M, THISSE C, THISSE B, RAZ, E (2001). A zebrafish nanos-related gene is essential for the development of primordial germ cells. Genes Dev 15 2877-2885.

LI M, TAN X, JIAO S, WANG Q, WU Z, YOU F, ZOU Y (2015). A new pattern of primordial germ cell migration in olive flounder (Paralichthys olivaceus) identified using nanos3. Dev Gene Evol 225: 195-206.

LIN F, XU S, MA D, XIAO Z, ZHAO C, XIAO Y, CHI L, LIU Q, LI J (2012). Germ line specific expression of a vasa homologue gene in turbot (Scophthalmus maximus) Evidence for vasa localization at cleavage furrows in euteleostei. Mol Reprod Dev 79: 803-813.

MISHIMA Y, GIRALDEZ AJ, TAKEDA Y, FUJIWARA T, SAKAMOTO H, SCHIER AF, INOUE K (2006). Differential Regulation of Germline mRNAs in Soma and Germ Cells by Zebrafish miR-430. Curr Biol 16: 2135-2142.

NAGASAWA K., FERNANDES J.M.O., YOSHIZAKI G., MIWA M., BABIAK I (2013). Identification and migration of primordial germ cells in atlantic salmon, Salmo salar. Characterization of vasa, dead end, and lymphocyte antigen 75 genes. Mol Reprod Dev 80: 118-131.

OTANI S, IWAI T, NAKAHATA S, SAKAI C, YAMASHITA M (2009). Artificial fertilization by intracytoplasmic sperm injection in a teleost fish, the medaka (Oryzias latipes). Biol Reprod 80: 175-183.

PRESSLAUER C, NAGASAWA K, FERNANDES JMO, BABIAK I (2012). Expression of vasa and nanos3 during primordial germ cell formation and migration in Atlantic cod (Gadus morthua L.). Theriogenology 78: 1262-1277.

SAITO T, GOTO-KAZETO R, ARAI K, YAMAHA E (2008). Xenogenesis in teleost fish through generation of germ-line chimeras by single primordial germ cell transplantation. Biol Reprod 78: 159-186

SAITO T, GOTO-KAZETO R, KAWAKAMI Y, NOMURA K, TANAKA H, ADACHI S ARAI K, YAMAHA E (2011). The mechanism for primordial germ-cell migration is conserved between Japanese eel and zebrafish. PLOS ONE 6 : e24460.

SAITOT, PSENICKAM, GOTO R, ADAHIS, INOUE K, ARAIK, YAMAHAE (2013). The origin and migration of primordial germ cells in sturgeons. PLOS ONE 9: e86861.

WAKAMATSU Y (1997). Preparation of medaka hatching enzyme. Fish Biol J Medaka 9: 49-50.

WESTERFIELD M (2007). THE ZEBRAFISHBOOK, $5^{\text {th }}$ edu. A guide for the laboratory use of zebrafish (Danio rerio), Eugene, University of Oregon Press.

YAMAGAMIK, HAMAZAKITS, YASUMASU S, MASUDAK, IUCHI I (1992). Molecular and cellular basis of formation, hardening, and breakdown of the egg envelope in fish. Int Rev Cytol 136: 51-92.

YAMAHA E, GOTO-KAZETO R, SAITO T, KAWAKAMI Y, FUJIMOTO T, ADACHI S ARAI K (2010). Primordial germ cell in teleost fish with special references to its specification and migration. J Appl Ichthyol 26: 816-822. 


\section{Further Related Reading, published previously in the Int. J. Dev. Biol.}

Intracllular localizations of the Dead End protein in Xenopus primordial germ cells

Ayaka Taguchi, Kenji Watanabe and Hidefumi Orii

Int. J. Dev. Biol. (2014) 58: 793-798

http://dx.doi.org/10.1387/ijdb.140308ho

Generation of germ-line chimera zebrafish using primordial germ cells isolated from cultured blastomeres and cryopreserved embryoids

Yutaka Kawakami, Rie Goto-Kazeto, Taiju Saito, Takafumi Fujimoto, Shogo Higaki, Yoshiyuki Takahashi, Katsutoshi Arai and Etsuro Yamaha Int. J. Dev. Biol. (2010) 54: 1493-1501

http://dx.doi.org/10.1387/ijdb.093059yk

Isolation of teleost primordial germ cells using flow cytometry

Rie Goto-Kazeto, Taiju Saito, Misae Takagi, Katsutoshi Arai and Etsuro Yamaha

Int. J. Dev. Biol. (2010) 54: 1487-1492

http://dx.doi.org/10.1387/ijdb.092914rg

Inter-species transplantation and migration of primordial germ cells in cyprinid fish Taiju Saito, Rie Goto-Kazeto, Takafumi Fujimoto, Yutaka Kawakami, Katsutoshi Arai and Etsuro Yamaha

Int. J. Dev. Biol. (2010) 54: 1481-1486

http://dx.doi.org/10.1387/ijdb.103111ts

Visulization of primordial germ cells in vivo using GFP-nos1 3'UTR mRNA

Taiju Saito, Takafumi Fujimoto, Shingo Maegawa, Kunio Inoue, Minoru Tanaka, Katsutoshi Arai and Etsuro Yamaha

Int. J. Dev. Biol. (2006) 50: 691-700

http://dx.doi.org/10.1387/ijdb.062143ts

5 yr ISI Impact Factor $(2013)=2.879$
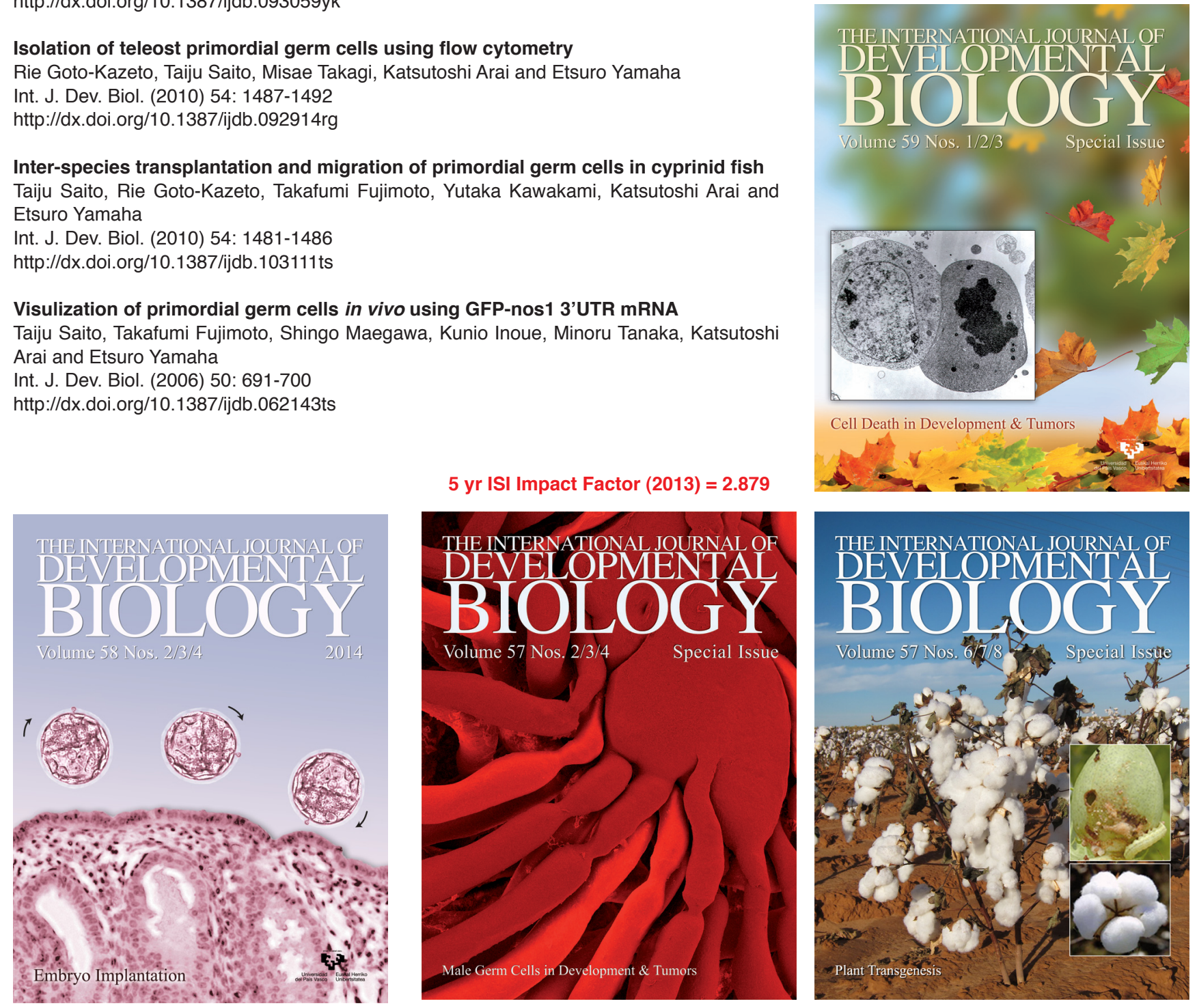